Document downloaded from:

http://hdl.handle.net/10251/63434

This paper must be cited as:

Muñoz-Galeano, N.; Alfonso Gil, JC.; Orts-Grau, S.; Segui-Chilet, S.; Gimeno Sales, FJ. (2015). Instantaneous approach to IEEE Std. 1459 power terms and quality indices. Electric Power Systems Research. 125:228-234. doi:10.1016/j.epsr.2015.04.012.

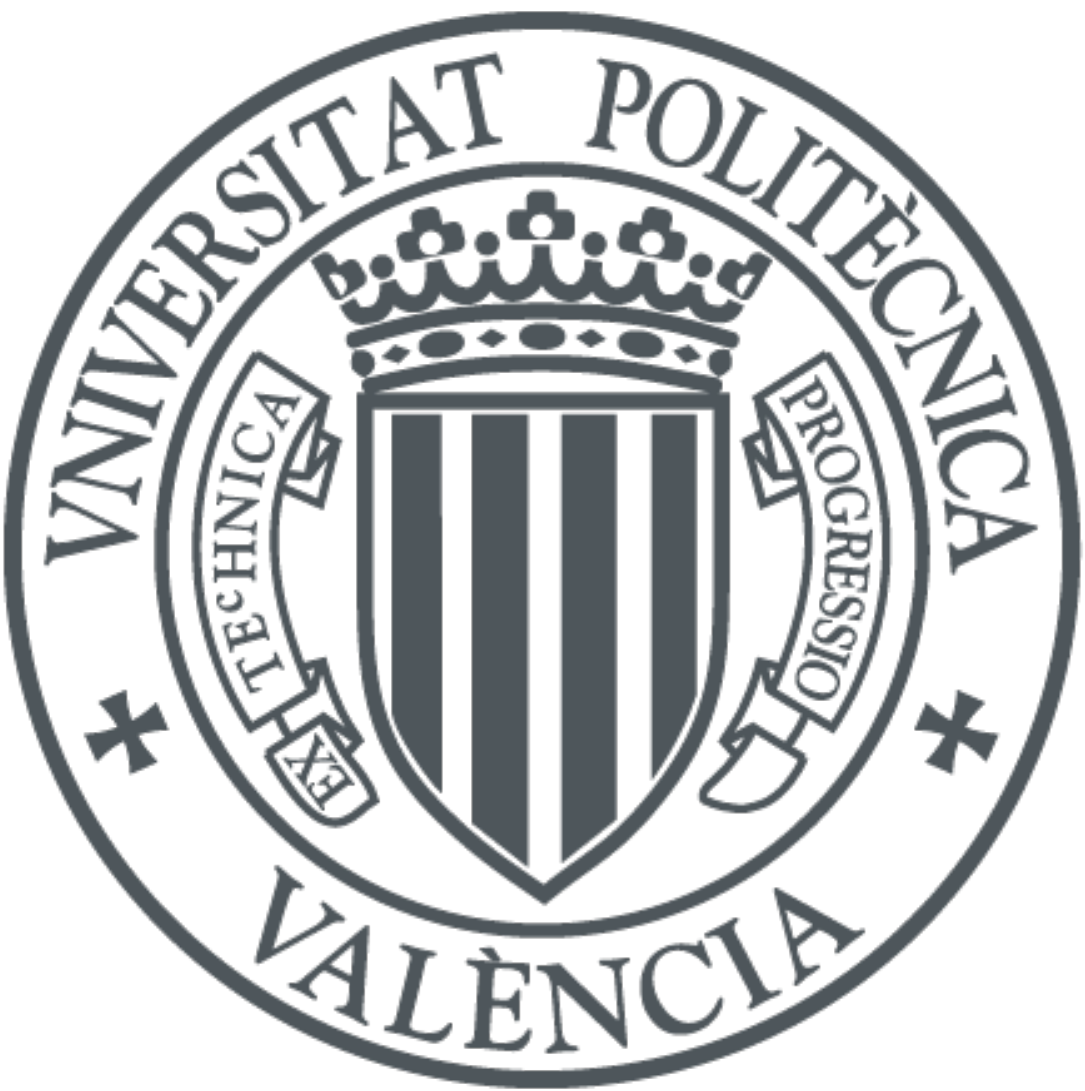

The final publication is available at

http://dx.doi.org/10.1016/j.epsr.2015.04.012

Copyright Elsevier

Additional Information 


\title{
Instantaneous approach to IEEE Std. 1459 power terms and quality indices
}

N. Muñoz-Galeano ${ }^{\mathrm{a}}$, J.C. Alfonso-Gil ${ }^{\mathrm{b}, *}$, S. Orts-Grau ${ }^{\mathrm{c}}$, S. Seguí-Chilet ${ }^{\mathrm{c}}$, F. J. GimenoSales ${ }^{c}$.

a Electrical Engineering Department, Universidad de Antioquia, Calle 67 Número 53108, Medellín-Colombia

${ }^{\mathrm{b}}$ Industrial Systems Engineering and Design Department, Universitat Jaume I de Castellón, Av. Vicent Sos Baynat s/n, 12071 Castellón de la Plana, Spain

${ }^{c}$ Electronic Engineering Department, Universitat Politècnica de València, Camino de Vera 14, 46022 Valencia, Spain

* Corresponding author. Tel.: +34 9647281 81. E-mail addresses: jalfonso@uji.es

\begin{abstract}
Based on an instantaneous analysis approach to the IEEE Std. 1459, the authors demonstrated in previous works that the effective apparent power should not be calculated including the rms neutral current and the rms line to line voltage terms. The use of these terms drives to expressions of power magnitudes that are overvaluated and disagree with well-accepted definitions. By using the instantaneous approach new power terms are proposed. Based on these terms, new power quality indices and new expressions of the unbalanced power terms are presented in this paper. An experimental case is used to compare the power magnitudes and power quality indices obtained with both approaches. Results demonstrate than the most significant power terms are over evaluated when IEEE Std. 1459 power definitions are used.
\end{abstract}

Keywords: IEEE Std. 1459, Power Quality Indices, Unbalanced Power, effective voltage, and effective current. 


\section{INTRODUCTION}

At present time, there is still not an universal consensus to quantify power in electrical systems. Power expressions are continuously improved obtaining more accurate expressions. The IEEE Std. 1459-2000 [1] presented a new power theory with an elegant decomposition of power terms. IEEE Std. 1459-2010 [2] was presented in 2010 as its most recently version. IEEE Std. 1459 includes definitions for the measurement of electric power quantities under sinusoidal, non-sinusoidal, balanced or unbalanced conditions, being explained its main ideas in [3-5]. In respect of previous standard, IEEE Std. 1459 separates fundamental and harmonic power terms and includes a power term that quantifies the effects of fundamental voltage asymmetries and fundamental current unbalances as part of the non-efficient powers.

Std. 1459 definitions are still under debate. A new resolution of the unbalance power $\left(S_{U 1}\right)$ has been presented in [6] and [7]. $S_{U 1}$ decomposition presented in [7] follows a similar decomposition to the one used in the IEEE Std. 1459 for the non-fundamental effective apparent power $\left(S_{e N}\right)$. Works presenting redefinitions of the power magnitudes or novel power quality indices can be found in the literature [8-15]. In [16] the author disagrees with the definition of the non-fundamental power, stating that "the definition of non-fundamental power S is flawed". In [17], some contradictions in useless active and reactive power were found when definitions of $V_{e}$ and $I_{e}$ included in the IEEE Std. 1459 are used. In [18] (section 6.4), for the calculation of the effective current $\left(I_{e}\right)$, the author suggests not to include the rms neutral current arguing that the rms currents $\left(I_{a}\right.$, $I_{b}, I_{c}$, e $I_{n}$ ) cause the conductors' heating, nevertheless, in overhead lines the heat transfer conditions for each line conductor is not affected by the currents flowing in the 
neutral conductor. In [19], effective power factors $\left(P F_{e}=P / S_{e}\right)$ larger than 1 were found when zero-sequence voltage components exist. One of the most significant standards, the DIN 40110-2: 2002-11 [20], defines the collective voltage $\left(V_{\Sigma}\right)$ (effective voltage for IEEE Std. 1459) as a function of rms line to neutral voltages without including the rms line to line voltages. Following an instantaneous approach based on wellestablished concepts used in IEEE Std. 1459, in [21] is proposed a new quantification of the unbalance power $\left(S_{U 1}\right)$, while in [22] is proposed a new quantification of the nonfundamental effective apparent power $\left(S_{e N}\right)$. The instantaneous power approach establishes a relationship between the instantaneous power flows, due to the different power terms, with the different power magnitudes that quantify the corresponding power terms. As a result of the instantaneous approach, new definitions of effective voltage $\left(V_{e}\right)$ and current $\left(I_{e}\right)$ are used to obtain the correct decomposition of all the power magnitudes defined in IEEE Std. 1459.

The analysis of non-sinusoidal and unbalanced electrical systems is still under research, as is demonstrated by field works [23-27]. By using the new power terms obtained through the instantaneous approach, new power quality indices and a new definition of the unbalanced power terms are presented in this paper. Also, an experimental case is analyzed using IEEE Std. 1459 power definitions and by mean of the instantaneous analysis approach to compare the power magnitudes and power quality indices obtained with both approaches. The results presented in this paper, complete the approach proposed by the authors in their previous works ([6], [7], [21], [22]).

The organization of the paper is as follows. In section 2, the instantaneous approach for the calculation of IEEE Std. 1459 power magnitudes [2] and unbalance power magnitudes [7] is summarized, based on new $V_{e}$ and $I_{e}$ definitions. In section 3, 
according to voltage, current, and power definitions proposed in the paper, new power quality indices are presented to measure the electric power quality. In section 4 some experimental results are presented using the instantaneous approach, being compared with the values obtained using IEEE Std. 1459 definitions. In section 5, the paper concludes with a summary of the main benefits that the instantaneous approach provides.

\section{IEEE STD. 1459 POWER MAGNITUDES BY MEANS OF AN INSTANTANEOUS POWER APPROACH}

A proper power theory should be understood from a basic level, must directly relate the power magnitudes with phenomena in electrical systems providing physical interpretation, and must establish equations and models that provide an accurate quantification of electrical magnitudes.

IEEE Std 1459 uses the instantaneous power expression in [1], p. 3, 4. In sections 3.1.1.1-3.1.1.3 the instantaneous approach is used to determine active and reactive components in linear single-phase systems. In section 3.2.1.1 is used to establish that the sum of the three instantaneous powers is equal to the active power $(P)$ when the three-phase system is sinusoidal (only contains fundamental components of the voltages and currents) and balanced. The instantaneous power approach in single-phase systems is necessarily used to define the power term that quantifies the reactive power. The instantaneous reactive power exists as a bidirectional power flow without an average value, being quantified by the peak value of the instantaneous reactive power. In threephase systems, the sum of the three single-phase instantaneous reactive powers yields to a nil power flow at any instant, which makes impossible to quantify this power terms by means of its average, as is done for the active power. 
The instantaneous power approach used in the IEEE Std. 1459 was extended in $[21,22]$ for unbalanced and non-linear three-phase systems. Three-phase power flows are analyzed in $[21,22]$ finding three different situations: a) power flows that have an average value that permits its quantification, as the active power; b) power flows with a nil average value but with a sinusoidal variation that permit their quantifications by means of the peak value of the oscillation, as occurs with some of the power flows quantified by means of the unbalance power; c) power flows with a nil average value and a nil instantaneous value, that are quantified by means of the sum of amplitudes of the single-phase oscillations, as occurs with the reactive power.

IEEE Std. 1459 resolution of $S_{e}, V_{e}$ and $I_{e}$ are presented in [1] section 3.2.4.3 as follows:

$$
\begin{aligned}
& I_{e}=\sqrt{\frac{I_{a}^{2}+I_{b}^{2}+I_{c}^{2}+I_{n}^{2}}{3}} \\
& V_{e}=\sqrt{\frac{1}{18}\left[3\left(V_{a}^{2}+V_{b}^{2}+V_{c}^{2}\right)+V_{a b}^{2}+V_{b c}^{2}+V_{c a}^{2}\right]} \\
& S_{e}=3 V_{e} I_{e}
\end{aligned}
$$

IEEE Std. 1459 power quantities are obtained by the resolution of $S_{e}, V_{e}$, and $I_{e}$ into different terms. Well-accepted power magnitudes are defined using the corresponding rms voltage and current terms: fundamental apparent, active, and reactive positivesequence powers $\left(S_{1}{ }^{+}, P_{1}{ }^{+}\right.$, and $Q_{1}{ }^{+}$respectively); harmonic active and reactive powers $\left(P_{H}\right.$ and $\left.Q_{H}\right)$; and current distortion power, voltage distortion power, and harmonic apparent power $\left(D_{e I}, D_{e V}\right.$, and $S_{e H}$ respectively). After the establishment of the effective power, new power magnitudes are defined by means of the subtraction of the previously defined power magnitudes. As an example, the unbalance power $\left(S_{U 1}\right)$ and the nonfundamental effective apparent power $\left(S_{e N}\right)$ are defined as follows:

$$
S_{U 1}^{2}=\left(S_{e 1}\right)^{2}-\left(S_{1}^{+}\right)^{2}
$$




$$
S_{e N}^{2}=S_{e}^{2}-S_{e 1}^{2}
$$

The IEEE Std 1459 approach has no complete physical meaning, and some power terms are in disagreement when are operated following the instantaneous approach presented in [21,22]. As demonstrated in [17], if IEEE Std. 1459 fundamental voltage and current definitions $\left(V_{e 1}\right.$ and $\left.I_{e 1}\right)$ are used, power magnitudes that include fundamental zerosequence components yield to expressions of active and reactive powers that disagree with IEEE Std. 1459 definitions. In [22], following a similar procedure, if IEEE Std. 1459 non-fundamental voltage and current definitions $\left(V_{e H}\right.$ and $\left.I_{e H}\right)$ are used, power magnitudes that include same-order, non-fundamental, and zero-sequence components yield to expressions of harmonic active and reactive powers that are in disagreement with IEEE Std. 1459 definitions. The problems arise as a $\sqrt{2}$ factor that multiplies the harmonic active and reactive power definitions. According to $[17,21,22]$ the instantaneous power approach provides full physical meaning and directly relates the power magnitudes with phenomena in electrical systems. The instantaneous power approach allows the correct quantification of the three-phase power flows, providing a power theory that can be simultaneously used for the development of improved measurement systems, engineering economic decisions, implementation of efficient active power compensators, and even detecting inefficient sources.

Based on the instantaneous power approach developed for fundamental unbalance [21], and for non-fundamental [22] three-phase systems, this section presents a summary of the revised IEEE Std. 1459 electric power quantities under sinusoidal, non-sinusoidal, balanced or unbalanced conditions. As a novelty, IEEE Std. 1459 power magnitudes included in [2] and the unbalance power magnitudes defined in [7] are redefined here taking into account the instantaneous power approach. A three-phase four-wire 
electrical system with a non-sinusoidal asymmetric supply and an unbalanced non-linear load is used in the paper to compare the power terms obtained by means of IEEE Std. 1459 and the instantaneous approach.

The instantaneous power approach starts from the definitions of the effective current $\left(I_{e \#)}\right)$ and the effective voltage $\left(V_{e \#)}\right)$ proposed by [22]. Following the same nomenclature used in [22], subscript "\#” denotes the magnitudes proposed by means of the instantaneous power approach. For a full physical meaning and following [20], $I_{e \#}$ is calculated without including the rms neutral current and $V_{e \# t}$ is calculated without including the rms line to line voltages as follows:

$$
\begin{gathered}
I_{e \#}=\sqrt{\frac{I_{a}^{2}+I_{b}^{2}+I_{c}^{2}}{3}} \\
V_{\text {e\# }}=\sqrt{\frac{V_{a}^{2}+V_{b}^{2}+V_{c}^{2}}{3}}
\end{gathered}
$$

With (6) and (7) a new expression of the effective apparent power $\left(S_{e \#}\right)$ is obtained:

$$
S_{e \#}=3 V_{e \# t} I_{e \#}=\sqrt{V_{a}^{2}+V_{b}^{2}+V_{c}^{2}} \sqrt{I_{a}^{2}+I_{b}^{2}+I_{c}^{2}}
$$

Power magnitudes are detailed separately in the next subsections for unbalanced linear loads (Subsection 2.1) and for non-linear loads (Subsection 2.2).

\subsection{Fundamental power magnitudes in three-phase unbalanced systems}

In this case the three-phase fundamental supply line to neutral voltages are not equal $\left(V_{a 1} \neq V_{b 1} \neq V_{c 1}\right) . V_{e \#}$ coincides with the fundamental effective voltage $\left(V_{e 1 \#}\right)$ because the supply voltage only contains fundamental components. $V_{e 1 \#}$ is calculated in terms of $V_{a 1}, V_{b 1}$, and $V_{c 1}$ as appears in (9). By means of the use of the symmetrical components, $V_{e 1 \#}$ is also calculated in (9) using the fundamental positive-, negative-, and zerosequence voltage components $\left(V_{1}^{+}, V_{1}^{-}\right.$, and $V_{1}^{0}$ respectively): 


$$
V_{e \# t}=V_{\text {el\# }}=\sqrt{\frac{V_{a 1}^{2}+V_{b 1}^{2}+V_{c 1}^{2}}{3}}=\sqrt{\left(V_{1}^{+}\right)^{2}+\left(V_{1}^{-}\right)^{2}+\left(V_{1}^{0}\right)^{2}}
$$

The fundamental currents through the unbalanced linear load are not equal $\left(I_{a 1} \neq I_{b 1} \neq I_{c 1}\right.$ and $\left.I_{n 1} \neq 0\right)$. In this case, $I_{e \#}$ coincides with the fundamental effective current $\left(I_{e 1 \#}\right) . I_{e 1 \#}$ is resolved in terms of $I_{a 1}, I_{b 1}$, and $I_{c 1}$ as appears in (10). By means of the use of the symmetrical components, $I_{e 1 \#}$ is also calculated in (10) using the fundamental positive-, negative-, and zero-sequence current components $\left(I_{1}{ }^{+}, I_{1}{ }^{-}\right.$, and $I_{1}{ }^{0}$ respectively):

$$
I_{\text {e\#t }}=I_{\text {el\# }}=\sqrt{\frac{I_{a 1}^{2}+I_{b 1}^{2}+I_{c 1}^{2}}{3}}=\sqrt{\left(I_{1}^{+}\right)^{2}+\left(I_{1}^{-}\right)^{2}+\left(I_{1}^{0}\right)^{2}}
$$

In this case, $S_{e \#}$ corresponds to the fundamental effective apparent power $\left(S_{e 1 \#)}\right)$, calculated as follows:

$$
S_{e \#}=S_{e l \#}=3 V_{\text {el\# }} I_{e l \#}
$$

The fundamental positive-sequence apparent power $\left(\mathrm{S}_{1}^{+}\right)$, active power $\left(\mathrm{P}_{1}^{+}\right)$, and reactive power $\left(Q_{1}{ }^{+}\right)$coincide with the expressions defined in the IEEE Std. 1459:

$$
\left(S_{1}^{+}\right)^{2}=\left(3 V_{1}^{+} I_{1}^{+} \cos \theta_{1}^{+}\right)^{2}+\left(3 V_{1}^{+} I_{1}^{+} \sin \theta_{1}^{+}\right)^{2}=\left(P_{1}^{+}\right)^{2}+\left(Q_{1}^{+}\right)^{2}
$$

According to [1], $P_{1}{ }^{+}$is the unique power term related to the energy delivery from the generator to the load. Due to that, $V_{1}^{+}$and the fundamental positive-sequence active current $\left(I_{1}{ }^{+}{ }^{a}=I_{1}{ }^{+} \cos \theta_{1}{ }^{+}\right)$are considered efficient and related to the useful transfer of energy.

The unbalance current $\left(I_{U 1 \#)}\right)$ is calculated in (13) by means of $I_{e 1 \#}$ and $I_{1}{ }^{+} . I_{U 1 \#}$ can be expressed in terms of the symmetrical components as follows:

$$
I_{U 1 \#}^{2}=I_{\text {el\# }}^{2}-\left(I_{1}^{+}\right)^{2}=\left(I_{1}^{-}\right)^{2}+\left(I_{1}^{0}\right)^{2}
$$

The unbalance voltage $\left(V_{U 1 \#}\right)$ is calculated in (14) by means of $V_{e 1 \#}$ and $V_{1}{ }^{+}$. $V_{U 1 \#}$ can be expressed in terms of the symmetrical components as follows: 


$$
V_{U 1 \#}^{2}=V_{\text {el\# }}^{2}-\left(V_{1}^{+}\right)^{2}=\left(V_{1}^{-}\right)^{2}+\left(V_{1}^{0}\right)^{2}
$$

The unbalance power $\left(S_{U 1 \#}\right)$ is calculated in (15) by means of $S_{e 1 \#}$ and $S_{1}{ }^{+}$. Following [7], $S_{U 1 \#}$ can be resolved into the voltage unbalance power $\left(S_{U 1 V}\right)$, the current unbalance power $\left(S_{U 1 I}\right)$, and the unbalance apparent power $\left(S_{U 1 U}\right)$ as follows:

$$
S_{U 1 \#}^{2}=\left(S_{\text {el\# }}\right)^{2}-\left(S_{1}^{+}\right)^{2}=S_{U 11 \#}^{2}+S_{U 11 \#}^{2}+S_{U 1 U \#}^{2}
$$

$S_{U 1 V \#}$ quantifies the power caused by voltage asymmetries, $S_{U 1 I \#}$ quantifies the power caused by current unbalances, and $S_{U 1 U \#}$ quantifies the power caused for both asymmetric voltages and unbalanced currents. Using the proposed expressions for $V_{U 1 \#}$ and $I_{U 1 \#}$, the power terms $S_{U 1 V \#}, S_{U 1 I \#}$, and $S_{U 1 U \#}$ are calculated by means of the instantaneous approach as follows:

$$
\begin{aligned}
& S_{U I V \#}^{2}=9 \cdot\left(V_{U I \#}\right)^{2} \cdot\left(I_{1}^{+}\right)^{2}=9 \cdot\left(\left(V_{1}^{-}\right)^{2}+\left(V_{1}^{0}\right)^{2}\right) \cdot\left(I_{1}^{+}\right)^{2} \\
& S_{U I I \#}^{2}=9 \cdot\left(V_{1}^{+}\right)^{2} \cdot\left(I_{U 1 \|}\right)^{2}=9 \cdot\left(V_{1}^{+}\right)^{2} \cdot\left(\left(I_{1}^{-}\right)^{2}+\left(I_{1}^{0}\right)^{2}\right) \\
& S_{U I U \#}^{2}=9 \cdot\left(V_{U I \#}\right)^{2} \cdot\left(I_{U I \#}\right)^{2}=9 \cdot\left(\left(V_{1}^{-}\right)^{2}+\left(V_{1}^{0}\right)^{2}\right) \cdot\left(\left(I_{1}^{-}\right)^{2}+\left(I_{1}^{0}\right)^{2}\right)
\end{aligned}
$$

When compared with the magnitudes defined in [7], this new resolution of $S_{U 1 \#}$ leads to lower values for the terms $S_{U 11 \#}$ and $S_{U 1 U \#}$, resulting in an overall reduction of $S_{U 1 \# \text {. With }}$ the use of the proposed $I_{e 1 \#}$ and $V_{e 1 \#}$, the fundamental power magnitudes are properly quantified. Also an extended resolution of the unbalance power is proposed, distinguishing between terms produced by voltage asymmetries or current unbalances. In [21] can be found the instantaneous analysis of the power flows and is demonstrated that using IEEE Std. 1459 some well-known power terms do not agree with their definition.

\subsection{Power magnitudes in a three-phase non-sinusoidal and unbalanced system}

In this case the supply voltages, including fundamental and harmonic components, are 
connected to an unbalanced non-linear load that demands fundamental and harmonic currents. $V_{e \#}$ is divided into $V_{e 1 \#}$ and the non-fundamental effective voltage $\left(V_{e H \#)}\right)$ as follows:

$$
V_{e \#}^{2}=V_{e l \#}^{2}+V_{e H \#}^{2}
$$

$V_{e 1 \#}$ is defined in (9). $V_{e H \#}$, by means of (7), is expressed as a function of the nonfundamental rms voltages from line to neutral as follows:

$$
V_{e H \#}=\sqrt{\frac{V_{a H}^{2}+V_{b H}^{2}+V_{c H}^{2}}{3}}
$$

Following the same approach for the currents, $I_{e \#}$ is resolved into $I_{e 1 \#}$ and the nonfundamental effective current $\left(I_{e H \#)}\right)$ as follows:

$$
I_{\text {e\# }}^{2}=I_{\text {el\# }}^{2}+I_{\text {eH\# }}^{2}
$$

$I_{e 1 \#}$ is defined in (10). $I_{e H \#}$, by means of (6), is expressed as a function of the nonfundamental rms phase currents as follows:

$$
I_{\text {eH\# }}=\sqrt{\frac{I_{a H}^{2}+I_{b H}^{2}+I_{c H}^{2}}{3}}
$$

Using the new expressions for effective voltages and currents (9), (10), (19), (21), the non-fundamental effective apparent power $\left(S_{e N \#}\right)$ is resolved in three terms as follows:

$$
S_{\text {eN\# }}^{2}=D_{e l \#}^{2}+D_{\text {eV\# }}^{2}+S_{\text {eH\# }}^{2}
$$

where $D_{e l \#}$ is the current distortion power (24), $D_{e V \#}$ is the voltage distortion power (25), and $S_{e H \#}(26)$ is the harmonic apparent power. $S_{e H \#}$ is resolved into $P_{H}$ and the harmonic distortion power $\left(D_{e H \#)}\right.$.

$$
\begin{aligned}
& D_{e l \#}^{2}=9 \cdot\left(V_{e l \#}\right)^{2} \cdot\left(I_{e H \#}\right)^{2} \\
& D_{e V \#}^{2}=9 \cdot\left(V_{e H \#}\right)^{2} \cdot\left(I_{e l \#}\right)^{2} \\
& S_{e H \#}^{2}=9 \cdot\left(V_{e H \#}\right)^{2} \cdot\left(I_{e H \#}\right)^{2}=P_{H}^{2}+D_{e H \#}^{2}
\end{aligned}
$$

$P_{H}$ and the harmonic reactive power $\left(Q_{H}\right)$, included into $D_{e H \#}$, are defined as in the IEEE 
Std. 1459:

$$
\begin{aligned}
& P_{H}=3 \sum_{h=2,3, \ldots, \infty} V_{h} \cdot I_{h} \cdot \cos \left(\theta_{h}\right) \\
& Q_{H}=3 \sum_{h=2,3, \ldots, \infty} V_{h} \cdot I_{h} \cdot \sin \left(\theta_{h}\right)
\end{aligned}
$$

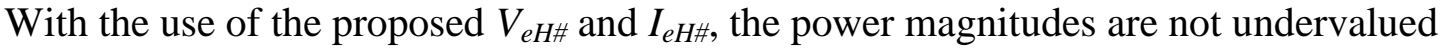
or overvalued. Also $P_{H}$ and $Q_{H}$, are in agreement with the expressions defined in the IEEE Std. 1459. In [22] can be found the instantaneous analysis of the power flows and is demonstrated that using IEEE Std. 1459 some well-known power terms do not agree with their correct definition.

\section{NEW POWER QUALITY INDICES UNDER THE INSTANTANEOUS APPROACH}

In order to improve the measurement of the electric power quality in electric installations, some IEEE Std. 1459 power quality indices are modified using the definitions proposed in the paper. A merit factor should compare inefficient magnitudes (magnitudes related to current and voltage phase shift, unbalance, and distortion) with useful magnitudes.

The proposed equivalent total harmonic distortion for voltage $\left(T H D_{e V \#}\right)$ and current $\left(T H D_{\text {el\# }}\right)$ must be defined in respect of the voltage and current terms that appear in the single one useful active power: $P_{1}^{+}$[2]. Both terms are defined as follows:

$$
\begin{gathered}
T H D_{e \mathrm{H}}=\frac{V_{e H \#}}{V_{1}^{+}} \\
T H D_{e l \#}=\frac{I_{e H \#}}{I_{1}^{+-a}}
\end{gathered}
$$

Factors $T H D_{e V \#}$ and $T H D_{e I \#}$ quantify the harmonic distortion of voltage and current waves respectively. $T H D_{e V \#}$ is defined as the ratio between $V_{e H \#}$ (voltage term related to 
distorted voltage waves) and $V_{1}^{+}$(useful voltage). $T H D_{\text {el\# }}$ is defined as the ratio between $I_{e H \#}$ (current term related to distorted current waves) and $I_{1}{ }^{+} a$ (the useful current component related to $P_{1}^{+}$).

The total voltage unbalance factor $\left(T U_{V}\right)$ quantifies the voltage asymmetries. The total current unbalance factor $\left(T U_{I}\right)$ quantifies the current unbalances. $T U_{V}$ and $T U_{I}$ were defined in [6] and now are redefined as follows:

$$
\begin{gathered}
T U_{V \#}=\frac{V_{U 1 \#}}{V_{1}^{+}} \\
T U_{\text {I\# }}=\frac{I_{U 1 \#}}{I_{1}^{+-a}}
\end{gathered}
$$

The effective power factor $\left(P_{F e \#}\right)$ is redefined in (33). $P_{F e \#}$ quantify the power quality in electrical systems, comparing the unique power that represent the useful transfer of power $\left(P_{1}^{+}\right)[2]$ with the global power demanded by loads $\left(S_{\text {e\#t }}\right)$ :

$$
P_{F e \# t}=\frac{P_{1}^{+}}{S_{\text {e\# }}}
$$

The proposed power magnitudes and power quality indices are useful for revenue purposes, engineering economic decisions, determination of the pollution source, and active compensators sizing.

\section{EXPERIMENTAL RESULTS}

The proposed resolution is applied to an experimental case where a symmetric and fundamental power supply is applied to an unbalanced and nonlinear load. Fig. 1 (left) shows the phase to neutral supply voltage waveforms $\left(v_{a_{-} s}, v_{b_{-} s}, v_{c_{-} s}\right)$ applied into load terminals. A comparison is performed between the different electrical magnitudes and power quality indices following the IEEE Std. 1459 and the instantaneous power approach. During the tests, the load rms fundamental line to neutral voltages $\left(V_{a 1}, V_{b 1}\right.$, 
and $V_{c 1}$ ) are balanced and approximately equal to $125 \mathrm{~V}$. Some voltage distortion is measured in the experimental tests due to power network normal conditions $\left(T H D_{e V}=1.97 \%\right)$.

The load used in the test is implemented using an unbalanced linear load in parallel with a balanced three-phase non-linear load. Fig. 1 (right) shows the load current waveforms (phases a-b-c and neutral from top to bottom). The waveforms are captured with a Lecroy Wavejet 324 oscilloscope. The balanced per-phase non-linear load is built using a single-phase uncontrolled rectifier with an LC filter and a resistive load $(L=5.0 \mathrm{mH}$, $C=2.2 \mathrm{mF}, R=100 \Omega$ ). The unbalanced linear load is connected from phase terminals (ab-c) to neutral wire (n) and has the following values:

- $\quad \mathrm{Z}_{\mathrm{a} \text { load }}=\left(\mathrm{R}_{\mathrm{a} \text { load }}=65.9 \Omega / / \mathrm{L}_{\mathrm{a} \text { load }}=67.2 \mathrm{mH}\right)$.

- $\quad \mathrm{Z}_{\mathrm{b} \text { load }}=\mathrm{L}_{\mathrm{c} \text { load }}=67.2 \mathrm{mH}$.

- $\quad \mathrm{Z}_{\mathrm{c} \text { load }}=\mathrm{L}_{\mathrm{c} \text { load }}=69.7 \mathrm{mH}$.

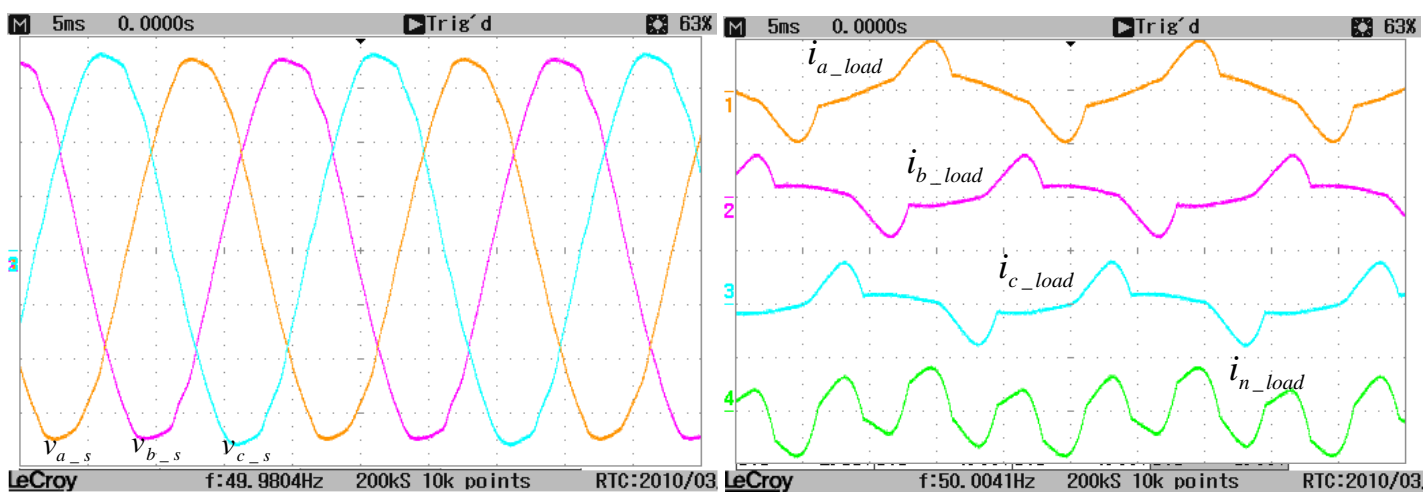

Fig. 1 Experimental supply voltages (left) and currents (right).

Table 1 shows a comparison between the voltages, currents, power magnitudes, and power quality indices in the load under IEEE Std. 1459 approach and under the instantaneous approach proposed in the paper. Some magnitudes give the same value under both approaches and magnitudes not defined in IEEE Std. 1459 include the label n.d. in the corresponding cell. 
Table 1: Experimental voltages, currents, power magnitudes, and power quality indices in the load.

\begin{tabular}{|c|c|c|c|}
\hline \multirow{2}{*}{$\begin{array}{c}V_{e}=127.19 \mathrm{~V} \\
V_{e \#}=127.20 \mathrm{~V}\end{array}$} & $V_{e 1}=127.15 \mathrm{~V}$ & $\mathrm{~V}_{\mathrm{eH}}=2.50 \mathrm{~V}$ & $V_{U 1}=$ n.d. \\
\hline & $V_{e 1 \#}=127.16 \mathrm{~V}$ & $\mathrm{~V}_{\mathrm{eH \#}}=2.92 \mathrm{~V}$ & $V_{U 1 \#}=1.66 \mathrm{~V}$ \\
\hline$I_{e}=4.87 \mathrm{~A}$ & $I_{e 1}=3.76 \mathrm{~A}$ & $\mathrm{I}_{\mathrm{eH}}=3.10 \mathrm{~A}$ & $I_{U 1}=$ n.d. \\
\hline$I_{e \#}=4.01 \mathrm{~A}$ & $I_{e 1 \#}=3.64 \mathrm{~A}$ & 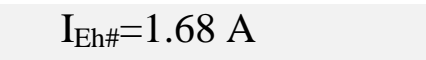 & $I_{U 1 \#}=0.83$. \\
\hline \multicolumn{2}{|c|}{$S_{1}^{+}=1350.33 \mathrm{VA}$} & $3.50 \mathrm{~W}$ & $Q_{1}^{+}=1350.33$ var \\
\hline \multicolumn{2}{|l|}{$S_{e}=1859.54 \mathrm{VA}$} & $40 \mathrm{VA} S_{e H}=23.29 \mathrm{VA}$ & $D_{e I}=1182.84 \mathrm{VA}$ \\
\hline \multicolumn{4}{|c|}{$S_{\text {e\# }}=1529.46 \mathrm{VA} S_{e 1 \#}=1387.62 \mathrm{VA} S_{e}$} \\
\hline$D_{e V}=28.24 \mathrm{VA}$ & $S_{U 1}=483.76 \mathrm{VA}$ & $T H D_{e I}=82.46 \%$ & $T H D_{e V}=1.97 \%$ \\
\hline$D_{e V \#}=31.81 \mathrm{VA}$ & $S_{U 1 \#}=319.52 \mathrm{VA}$ & $T H D_{\text {eI\# }}=46.29 \%$ & $T H D_{e V \#}=2.29 \%$ \\
\hline
\end{tabular}

The effective voltages $\left(V_{e}, V_{e 1}, V_{e H}\right)$ are defined in the IEEE Std. 1459 as a function of the rms line to neutral voltages and the rms line to line voltages. Due to rms line to line voltages do not include the zero-sequence voltage components, IEEE Std. 1459 terms $\left(V_{e}, V_{e 1}, V_{e H}\right)$ are undervalued respect to the proposed effective voltages $\left(V_{e \#}, V_{e 1 \#}, V_{e H \#}\right)$. The small differences in the case under analysis are explained because the measurements are done in the real power network available in our laboratories. It includes with very low voltage harmonic components (quantified by $V_{e H}$ ) and asymmetries (quantified by $V_{U 1 \#)}$ ).

The values of the proposed effective currents $\left(I_{e \#}, I_{e 1 \#}, I_{e H \#}\right)$ are lower than the IEEE Std 1459 effective currents $\left(I_{e}, I_{e 1}, I_{e H}\right) . I_{e}, I_{e 1}, I_{e H}$ are defined as a function of the phase and neutral rms currents and the inclusion of the rms neutral current causes an overvaluation of $21.6 \%$ for $I_{e}$, a $3.4 \%$ for $I_{e 1}$, and an $84.2 \%$ for $I_{e H}$, in relation to $I_{e \# \#}, I_{e 1 \#}, I_{e H \#}$ respectively.

Undervalued voltages and overvalued currents cause, in the case under analysis, the overvaluation of $S_{e}(21.6 \%), S_{e 1}(3.4 \%), S_{e N}(84.0 \%), S_{e H}(58.1 \%), D_{e I}(84.2 \%), S_{U 1}$ 
(51.4\%), and $T H D_{e I}(78.1 \%)$. The power $D_{e V}(-11.2 \%)$ and the distortion $T H D_{e V}$ $(-14 \%)$ are undervalued due to their dependence on $V_{e H}$. The undervaluation is represented with the minus sign.

Table 2 shows a comparison between the voltages, currents, power magnitudes, and power quality indices in the system under the approach proposed in [21] (following IEEE Std. 1459 decomposition of power terms) and under the instantaneous approach, first proposed in [22].

Table 2: Unbalance voltages, currents, power magnitudes, and power quality indices in the load.

\begin{tabular}{ccc}
\hline$V_{U 1}=1.31 \mathrm{~V}$ & $I_{U 1}=1.26 \mathrm{~A}$ & $S_{U 1}=483.76 \mathrm{VA}$ \\
$V_{U 1 \#}=1.67 \mathrm{~V}$ & $I_{U 1 \#}=0.84 \mathrm{~A}$ & $S_{U 1}=319.52 \mathrm{VA}$ \\
$S_{U 1 U}=4.99 \mathrm{VA}$ & $S_{U 1 I}=483.54 \mathrm{VA}$ & $S_{U 1 V}=13.94 \mathrm{VA}$ \\
$S_{U 1 U \#}=4.18 \mathrm{VA}$ & $S_{U 1 I \#}=319.01 \mathrm{VA}$ & $S_{U 1 \mathrm{~V}}=17.69 \mathrm{VA}$ \\
$T U_{I}=45.49 \%$ & $T U_{V}=1.03 \%$ & $P_{F e}=$ n.d. \\
$T U_{I \#}=30.01 \%$ & $T U_{V \#}=1.31 \%$ & $P_{F e \#}=0.69$ \\
\hline
\end{tabular}

The unbalance approach proposed by [21] yields to expressions of $V_{U 1}$ undervalued $(-21.5 \%)$ and $I_{U 1}$ overvalued (50\%). In this case, $S_{U 1}(51.4 \%), S_{U 1 U}(19.4 \%)$, and $S_{U 1 I}$ $(51.6 \%)$ are overvalued while $S_{U 1 V}(-21.2 \%)$ is undervalued, always when are compared with their corresponding values under the instantaneous approach.

It seems that values of $T U_{I}$ and $T U_{V}$ do not follow the criterion that IEEE Std. 1459 terms related to voltages are undervalued while terms related to currents are overvalued. It is due to $T U_{I}$ and $T U_{V}$ are defined in the instantaneous approach using different current and voltage terms. $T U_{I}$ proposed in [7] compares $I_{U 1}$ with $I_{e 1}$, while $T U_{I \#}$ compares $I_{U 1 \#}$ with $I_{1}{ }^{+}{ }^{a}$. With the proposed definition $T U_{I \#}$ results lower than $T U_{I}$ in this case. $I_{e 1}$, must not be used in the calculation of $T U_{I}$ due to $I_{e 1}$ is including $I_{1}^{-}$and $I_{1}{ }^{0}$, terms that are related to the current unbalance. A similar consideration can be done for 
$T U_{V} . T U_{V}$ proposed in [7] compares $V_{U 1}$ with $V_{e 1}$, while $T U_{V \#}$ compares $V_{U 1 \#}$ with $V_{1}^{+}$, resulting in values of $T U_{V}$ smaller than the obtained for $T U_{V \# .} V_{e 1}$, must not be used in the calculation of $T U_{V}$ due to $V_{e 1}$ is including $V_{1}^{-}$and $V_{1}^{0}$, terms that are related to the voltage asymmetries.

The value of $T U_{I}$ is higher than the value of $T U_{V}$, both defined in [21]. The value of $T U_{\text {I\# }}$ is also higher than the value of $T U_{V \# .}$ Both approaches indicate that the fundamental current unbalance is larger than the fundamental voltage asymmetry. The factor $P_{F e}$ is less than 1, indicating the presence of useless powers in the electrical system.

\section{CONCLUSIONS}

This paper proposes new expressions of effective voltage $\left(V_{e \#)}\right)$ and effective current $\left(I_{e \#}\right)$ that are determined by means of the analysis of instantaneous power flows in electrical systems. In comparison with IEEE Std. 1459, $V_{\text {e\# }}$ is defined without including rms line to line voltages and $I_{e \sharp}$ is defined without including the neutral current. By means of the new expressions of $V_{e \#}$ and $I_{e \#}$, several power magnitudes included in the IEEE Std. 1459 have been redefined. Also power terms included in the latest decomposition of the unbalance power are redefined following the instantaneous approach.

The correct quantification of power magnitudes is mandatory for revenue purposes, where the final users have to pay overcharges for the non-efficient power terms that are present in their installations. Also the correct quantification of power magnitudes has effect in the sizing of the active power compensator that can reduce or eliminate the non-efficient power terms demanded in an installation.

An experimental case is analyzed using IEEE Std. 1459 power definitions and by mean 
of the instantaneous analysis approach summarized in this paper. Results demonstrate than the most significant power terms are overvaluated when IEEE Std. 1459 power definitions are used. Also new unbalance power definitions $\left(S_{U 1 V}, S_{U 1 I}, S_{U 1 U}\right)$ are included in the study.

The IEEE Std. 1459 effective voltages $\left(V_{e}, V_{e 1}, V_{e H}\right)$ are undervalued due to include in their expressions line to line voltages, while the IEEE Std. 1459 effective currents $\left(I_{e}\right.$, $\left.I_{e 1}, I_{e H}\right)$ are overvalued due to include in their expressions the neutral current. The power magnitudes that depend on effective currents are overvalued and the power magnitudes that depend on effective voltage are undervalued.

The use of the proposed $V_{e \#}$ and $I_{e \#}$ provides the right quantification of all the power magnitudes that exist in electric power systems under sinusoidal, non-sinusoidal, balanced or unbalanced conditions. The proposed power quality indices compare inefficient magnitudes with useful magnitudes permitting the proper power quality evaluation in power networks.

The definitions of IEEE Std. 1459 following the proposed instantaneous approach can provide a simultaneous common base for revenue purposes, evaluation of electric energy quality, engineering economic decisions, determination of major harmonic polluters, and design of mitigation equipment such as active compensators.

\section{ACKNOWLEDGMENTS}

The authors wish to thank the support offered by the "Estrategia de sostenibilidad 20142015" University of Antioquia (Colombia), as well as the support of the Ministerio de Economía y Competitividad of Spain (grant DPI2011-28606). 


\section{ANNEX}

The load voltages and currents components are included in the following tables.

These values have been used for the calculation of the voltage, current, and power terms included in tables 1 and 2. The calculations have done using the method described in [28]. The origin of angles is $V_{1}^{+}$in phase $a$.

Table 3: Voltages (V), currents (A), and THDs (\%) obtained in the load terminals.

\begin{tabular}{llll}
\hline$V_{a}=125.46$ & $V_{a 1}=125.44$ & $V_{a H}=2.49$ & $T H C_{V a}=1.95$ \\
$V_{b}=126.82$ & $V_{b 1}=126.78$ & $V_{b H}=3.24$ & $T H C_{V b}=2.56$ \\
$V_{c}=129.26$ & $V_{c 1}=129.23$ & $V_{c H}=3.00$ & $T H C_{V c}=2.32$ \\
$V_{a b}=218.82$ & $V_{a b 1}=218.79$ & $V_{a b H}=3.60$ & $T H C_{V a b}=1.65$ \\
$V_{b c}=220.95$ & $V_{b c 1}=220.92$ & $V_{b c H}=3.24$ & $T H C_{V b c}=1.47$ \\
$V_{c a}=220.85$ & $V_{c a 1}=220.82$ & $V_{c a H}=3.59$ & $T H C_{V c a}=1.63$ \\
$I_{a}=4.83$ & $I_{a 1}=4.52$ & $I_{a H}=1.70$ & $T H C_{l a}=37.61$ \\
$I_{b}=3.54$ & $I_{b 1}=3.14$ & $I_{b H}=1.64$ & $T H C_{l b}=52.23$ \\
$I_{c}=3.52$ & $I_{c 1}=3.08$ & $I_{c H}=1.71$ & $T H C_{l c}=55.52$ \\
$I_{n}=4.80$ & $I_{n 1}=1.65$ & $I_{n H}=4.51$ & $T H C_{l n}=273.33$ \\
\hline
\end{tabular}

Table 4: Fundamental and first harmonic components of the load voltages (V) and currents (A) (magnitude and phase-shift)

\begin{tabular}{|c|c|c|c|c|}
\hline $\mathbf{h}$ & Phase A & Phase B & Phase C & Neutral \\
\hline 1 & $\begin{array}{c}V_{a 1}=125.44 V \angle 0^{\circ} \\
I_{a 1}=4.52 \mathrm{~A} \angle-28.62^{\circ}\end{array}$ & $\begin{array}{c}V_{b 1}=126.78 V \angle-120.35^{\circ} \\
I_{b 1}=3.14 \mathrm{~A} \angle-166.18^{\circ}\end{array}$ & $\begin{array}{c}V_{c 1}=129.23 \mathrm{~V} \angle-239.74^{\circ} \\
I_{c 1}=3.08 \mathrm{~A} \angle-283.65^{\circ}\end{array}$ & $I_{n 1}=1.65 A \angle 2.59^{\circ}$ \\
\hline 3 & $\begin{array}{c}V_{a 3}=1.63 V \angle 26.93^{\circ} \\
I_{a 3}=1.53 \mathrm{~A} \angle 100.58^{\circ}\end{array}$ & $\begin{aligned} V_{b 3} & =2.51 V \angle 36.47^{\circ} \\
I_{b 3} & =1.45 \mathrm{~A} \angle 92.69^{\circ}\end{aligned}$ & $\begin{array}{l}V_{c 3}=2.29 V \angle 54.04^{\circ} \\
I_{c 3}=1.53 \mathrm{~A} \angle 97.56^{\circ}\end{array}$ & $I_{n 3}=4.5 \mathrm{~A} \angle 5.15^{\circ}$ \\
\hline 5 & $\begin{array}{l}V_{a 5}=1.66 V \angle 109.05^{\circ} \\
I_{a 5}=0.68 A \angle 211.90^{\circ}\end{array}$ & $\begin{aligned} V_{b 5} & =1.83 V \angle 238.15^{\circ} \\
I_{b 5} & =0.69 A \angle 41.24^{\circ}\end{aligned}$ & $\begin{array}{l}V_{c 5}=1.82 V \angle 15.77^{\circ} \\
I_{c 5}=0.73 \mathrm{~A} \angle 88.21^{\mathrm{o}}\end{array}$ & $I_{n 5}=0.09 A \angle 155.54^{\circ}$ \\
\hline 7 & $\begin{aligned} V_{a 7} & =0.45 V \angle 258.83^{\circ} \\
I_{a 7} & =0.24 A \angle 82.28^{\circ}\end{aligned}$ & $\begin{array}{l}V_{b 7}=0.59 \mathrm{~V} \angle 197.05^{\circ} \\
I_{b 7}=0.29 \mathrm{~A} \angle 143.16^{\circ}\end{array}$ & $\begin{array}{l}V_{c 7}=0.23 \mathrm{~V} \angle 88.58^{\circ} \\
I_{c 7}=0.26 \mathrm{~A} \angle 39.00^{\circ}\end{array}$ & $I_{n 7}=0.09 \mathrm{~A} \angle-3.72^{\circ}$ \\
\hline 9 & $\begin{aligned} V_{a 9} & =0.60 V \angle 194.14^{\circ} \\
I_{a 9} & =0.19 A \angle 10.54^{\circ}\end{aligned}$ & $\begin{aligned} V_{b 9} & =0.76 V \angle 183.51^{\circ} \\
I_{b 9} & =0.21 \mathrm{~A} \angle 27.56^{\circ}\end{aligned}$ & $\begin{aligned} V_{c 9} & =0.76 V \angle 184.62^{\circ} \\
I_{c 9} & =0.20 \mathrm{~A} \angle 15.98^{\circ}\end{aligned}$ & $I_{c 1}=0.59 \mathrm{~A} \angle-109.43^{\circ}$ \\
\hline
\end{tabular}

The symmetrical components for the case under analysis are the following:

$$
\begin{array}{lll}
\hline I_{1}{ }^{+}=3.54 \mathrm{~A} & I_{1}^{-}=0.63 \mathrm{~A} & I_{1}{ }^{0}=0.55 \mathrm{~A} \\
V_{1}{ }^{+}=127.15 \mathrm{~V} & V_{1}^{-}=0.82 \mathrm{~V} & V_{1}^{0}=1.45 \mathrm{~V} \\
\hline
\end{array}
$$




\section{REFERENCES}

[1] IEEE Trial-Use Standard Definitions for the Measurement of Electric Power Quantities Under Sinusoidal, Non-sinusoidal, Balanced, Or Unbalanced Conditions 2000:i-44. doi:10.1109/IEEESTD.2000.93398.

[2] IEEE Standard Definitions for the Measurement of Electric Power Quantities Under Sinusoidal, Nonsinusoidal, Balanced, or Unbalanced Conditions 2010:150. doi:10.1109/IEEESTD.2010.5439063.

[3] Emanuel AE. Summary of IEEE Standard 1459: Definitions for the Measurement of Electric Power Quantities Under Sinusoidal, Nonsinusoidal, Balanced, or Unbalanced Conditions. IEEE Trans Ind Appl 2004;40:869-76. doi:10.1109/TIA.2004.827452.

[4] L Willems J. The IEEE standard 1459: What and why? 2010 IEEE Int. Work. Appl. Meas. Power Syst., IEEE; 2010, p. 41-6. doi:10.1109/AMPS.2010.5609324.

[5] Emanuel AE. The Randomness Power: An Other New Quantity to be Considered. 2007 IEEE Power Eng. Soc. Gen. Meet., IEEE; 2007, p. 1-6.

[6] Orts-grau S, Alfonso-Gil JCJC, Gimeno-sales FJFJ, Segui-chilet S. New Resolution of the Unbalance Power According to Std. 1459. IEEE Trans Power

[7] Orts-Grau S, Munoz-Galeano N, Alfonso-Gil JC, Segui-Chilet S, Gimeno-Sales FJ. Meaningful Resolution of the IEEE Std. 1459 Unbalanced Power. IEEE Trans Power Syst 2011;26:1783-4. doi:10.1109/TPWRS.2010.2091326. 
[8] De Almeida JEL, da Silveira PM, de Abreu JPG, Arango H. A new IEEE Std 1459-2000 - Compatible time-domain formulation for apparent power. Electr Power Syst Res 2009;79:505-10. doi:10.1016/j.epsr.2008.09.001.

[9] Morsi WG, El-Hawary ME. Reformulating Three-Phase Power Components Definitions Contained in the IEEE Standard 1459-2000 Using Discrete Wavelet Transform. IEEE Trans Power Deliv 2007;22:1917-25. doi:10.1109/TPWRD.2007.899776.

[10] Morsi WG, El-Hawary ME. A new reactive, distortion and non-active power measurement method for nonstationary waveforms using wavelet packet transform. Electr Power Syst Res 2009;79:1408-15. doi:10.1016/j.epsr.2009.04.018.

[11] Morsi WG, El-Hawary ME. Novel power quality indices based on wavelet packet transform for non-stationary sinusoidal and non-sinusoidal disturbances. Electr Power Syst Res 2010;80:753-9. doi:10.1016/j.epsr.2009.11.005.

[12] Will NC, Cardoso R. Implementation of the IEEE Std 1459-2010 using Kalman filter for fundamental and harmonics detection. 2012 3rd IEEE PES Innov. Smart Grid Technol. Eur. (ISGT Eur., IEEE; 2012, p. 1-7. doi:10.1109/ISGTEurope.2012.6465729.

[13] Zolfaghari R, Shrivastava Y, Agelidis VG. A comparison between different windows in spectral and cross spectral analysis techniques with Kalman filtering for estimating power quality indices. Electr Power Syst Res 2012;84:128-34. doi:10.1016/j.epsr.2011.10.017. 
[14] Zolfaghari R, Shrivastava Y, Agelidis VG. Evaluation of windowed ESPRIT virtual instrument for estimating Power Quality Indices. Electr Power Syst Res 2012;83:58-65. doi:10.1016/j.epsr.2011.09.009.

[15] Cataliotti A, Cosentino V. A New Measurement Method for the Detection of Harmonic Sources in Power Systems Based on the Approach of the IEEE Std. 1459-2000. IEEE Trans Power Deliv 2010;25:332-40. doi:10.1109/TPWRD.2009.2034480.

[16] Hughes MB. Electric power measurements-a utility's perspective. IEEE Power Eng. Soc. Summer Meet., vol. 3, IEEE; 2002, p. 1680-1. doi:10.1109/PESS.2002.1043676.

[17] Orts-Grau S, Munoz-Galeano N, Alfonso-Gil JC, Gimeno-Sales FJ, Segui-Chilet S. Discussion on Useless Active and Reactive Powers Contained in the IEEE Standard 1459. IEEE Trans Power Deliv 2011;26:640-9. doi:10.1109/TPWRD.2010.2096519.

[18] Power Definitions and the Physical Mechanism of Power Flow. Wiley-IEEE Press; 1 edition; 2010.

[19] Willems JL, Ghijselen JA, Emanuel AE. The Apparent Power Concept and the IEEE Standard 1459-2000. IEEE Trans Power Deliv 2005;20:876-84. doi:10.1109/TPWRD.2005.844267.

[20] DIN 40110-2:2002-11. Circuits, Quantities Used in Alternating Current TheoryPart 2: Multi-Line 2002.

[21] Seguí-Chilet S, Gimeno-Sales FJ, Orts S, Garcerá G, Figueres E, Alcañiz M, et al. Approach to unbalance power active compensation under linear load 
unbalances and fundamental voltage asymmetries. Int J Electr Power Energy Syst 2007;29:526-39. doi:10.1016/j.ijepes.2007.01.003.

[22] Muñoz-Galeano N, Alfonso-Gil JC, Orts-Grau S, Seguí-Chilet S, Gimeno-Sales FJ. Non-fundamental effective apparent power defined through an instantaneous power approach. Int J Electr Power Energy Syst 2011;33:1711-20. doi:10.1016/j.ijepes.2011.08.013.

[23] Czarnecki LS, Pearce SE. Compensation objectives and Currents' Physical Components-based generation of reference signals for shunt switching compensator control. IET Power Electron 2009;2:33-41. doi:10.1049/ietpel:20070388.

[24] Morsi WG, El-Hawary ME. Defining Power Components in Nonsinusoidal Unbalanced Polyphase Systems: The Issues. IEEE Trans Power Deliv 2007;22:2428-38. doi:10.1109/TPWRD.2007.905344.

[25] Seong-Jeub Jeon. Unification and Evaluation of the Instantaneous Reactive Power Theories. 37th IEEE Power Electron. Spec. Conf., IEEE; 2006, p. 1-7. doi:10.1109/PESC.2006.1712055.

[26] Spath H. A general purpose definition of active current and non-active power based on German standard DIN 40110. Electr Eng 2007;89:167-75.

[27] Willems J. The fundamental concepts of power theories for single-phase and three-phase voltages and currents: Part 27 in a series of tutorials on instrumentation and measurement. IEEE Instrum Meas Mag 2010;13:37-44. doi:10.1109/MIM.2010.5585073.

[28] Alfonso-Gil JC, Orts-Grau S, Munoz-Galeano N, Gimeno-Sales FJ, Segui-Chilet S. Measurement System for a Power Quality Improvement Structure Based on 
IEEE Std.1459. IEEE Trans Instrum Meas 2013;PP:1-1. doi:10.1109/TIM.2013.2270901. 